\title{
Molecular and Crystal Structure of Poly(vinylidene chloride)
}

\author{
Takayuki TAKAHAGI, * Yozo ChATANI,** Takao KusUmoto, \\ and Hiroyuki TADOKORO \\ Department of Macromolecular Science, Faculty of Science, \\ Osaka University, Toyonaka, Osaka 560, Japan
}

(Received May 18, 1988)

\begin{abstract}
The molecular and crystal structure of poly(vinylidene chloride) were determined by X-ray structure analysis together with conformational energy calculation. The crystals are monoclinic $\mathrm{P} 2_{1}$ or $\mathrm{P} 2_{1} / \mathrm{m}$ with cell dimensions $a=6.71 \AA, b$ (fiber axis) $=4.68 \AA, c=12.51 \AA$, and $\beta=$ $123^{\circ}$, and there are four monomeric units (two chains) in the unit cell. The molecular conformation is a glide $(T G T \bar{G})$ form: the internal rotation angles of two successive backbone bonds are $175^{\circ}(T)$ and $49^{\circ}\left(G^{\prime}\right)$, and the $\mathrm{C}-\mathrm{CH}_{2}-\mathrm{C}$ and $\mathrm{C}-\mathrm{CCl}_{2}-\mathrm{C}$ bond angles are $123^{\circ}$ and $114^{\circ}$, respectively. The deviation of the internal rotation angle from $60^{\circ}(G)$ to $49^{\circ}\left(G^{\prime}\right)$ and the large $\mathrm{C}-\mathrm{CH}_{2}-\mathrm{C}$ bond angle are ascribable to the steric hindrance between the chlorine atoms of adjacent monomeric units. From the X-ray study, the great possibility of a disorder with respect to the packing of upward and downward chains in the crystal lattice (space group $P 2_{1} / \mathrm{m}$ ) is inferred.

KEY WORDS Poly(vinylidene chloride) / X-Ray Analysis / Crystal Structure / Molecular Structure / Canal Polymerization / $\gamma$-Ray Irradiation / Vinylidene Chlorode-Thiourea Adduct / Conformation Energy /
\end{abstract}

Several molecular models of poly(vinylidene chloride) (PVDC) have been proposed in order to account for the fiber period of $4.7 \AA$ which is appreciably shorter than the repeat distance of two monomeric units in the fully extended zigzag form, 5.1 $\AA$. Fuller ${ }^{1}$ suggested an alternatively twisted zigzag model, while Reinhardt ${ }^{2}$ proposed a tub form with an alternate repetition of cis and trans conformations. De Santis et al. $^{3-5}$ proposed a $2 / 1$ helical model based upon conformational energy calculation and optical transform technique. By means of calculation of normal vibration, Miyazawa and Ideguchi $^{6}$ proposed a glide model with $T G T \bar{G}$ conformation which was again supported by Hendra and Mackenzie ${ }^{7}$ by Raman study. Employing a combination of
FT-IR and Raman studies and geometric consideration, Coleman et al.$^{8-10}$ concluded that a $T X T \bar{X}$ chain conformation is favored. The problem on the crystal structure of PVDC has not yet been settled with certainly, though Reinhardt ${ }^{2}$ and Okuda ${ }^{11,12}$ independently proposed different monoclinic cells. In the present paper, we will report the molecular and crystal structure of PVDC obtained by Xray structure analysis together with conformational energy calculation.

\section{EXPERIMENTAL}

\section{Sample}

Since it was rather difficult to prepare a well oriented PVDC homopolymer specimen by

\footnotetext{
* Present address: Toray Research Center, Inc., Otsu, Shiga 520, Japan.

Corresponding should be addressed.

** Present address: Department of Material Systems Engineering, Faculty of Technology, Tokyo University of Agriculture and Technology, Koganei, Tokyo 184, Japan.
} 
drawing, so-called "canal polymerization method" 13 was employed for single crystals of the vinylidene chloride-thiourea adduct to obtain highly oriented PVDC homopolymer specimens suitable for $\mathrm{X}$-ray measurements. The canal polymerization was carried out by the following procedure. First, needle-like single crystals of the vinylidene chloride-thiourea adduct were grown from a mixture of methanol solution of thiourea $(4 \mathrm{wt} \%, 10 \mathrm{ml})$ and vinylidene chloride $(4.6 \mathrm{ml})$ by cooling to $-20^{\circ} \mathrm{C}$. The monomer-thiourea adduct was then converted into the poly(vinylidene chloride)-thiourea adduct on $\gamma$-ray irradiation (total dose; $2 \mathrm{Mrad}$ ) at $-78^{\circ} \mathrm{C}$. Uniaxially oriented PVDC filaments were obtained by washing out the thiourea from the adduct single crystals with hot water. PVDC filaments suitable for X-ray measurements with dimensions, say $0.15 \mathrm{~mm}$ in diameter and $10 \mathrm{~mm}$ in length, were selected. The infrared spectrum of this polymer was in accordance with that of PVDC homopolymer obtained by usual way.

\section{$X$-Ray Measurement}

Nickel-filtered $\mathrm{Cu} K_{\alpha}$ radiation was used throughout this study. X-Ray photographs were taken with a cylindrical camera with a radius of $45 \mathrm{~mm}$ or $50 \mathrm{~mm}$. A fiber photograph of the canal-polymerized PVDC filament is shown in Figure 1. The number of observed reflections was 34 . Observed $d$-spacings were calibrated with reference to those of aluminum powder. The reflection intensities taken by the multiple-film method were measured by visual comparison with a standard intensity scale. The correction for the single crystal rotation Lorentz-polarization factor was made to the observed intensities.

\section{STRUCTURE ANALYSIS}

\section{Conformational Energy}

In this study, the conformational energy for the PVDC chain with the observed identity period of $4.68 \AA$, in which two monomeric units are contained, was evaluated varying the $\mathrm{C}-\mathrm{CH}_{2}-\mathrm{C}$ and $\mathrm{C}-\mathrm{CCl}_{2}-\mathrm{C}$ bond angles, and this procedure made it possible to examine the various molecular models proposed so far on one energy contour map as shown in Figure 2.

In the energy calculation, besides internal rotation barrier, van der Waals interaction, and electrostatic interaction, bending energy was also taken into account. The constrained conditions in the calculation were as follows; (1) the $\mathrm{Cl}-\mathrm{C}-\mathrm{Cl}$ and $\mathrm{H}-\mathrm{C}-\mathrm{H}$ bond angles were fixed at the tetrahedral value, (2) the $\mathrm{C}-\mathrm{C}$, $\mathrm{C}-\mathrm{Cl}$, and $\mathrm{C}-\mathrm{H}$ bond lengths were assumed to be $1.54,1.78$, and $1.09 \AA$, respectively, and (3) two monomeric units in the identity period were equivalent to each other, in other words, the PVDC chain has either a twofold screw axis or a glide plane along the chain axis.

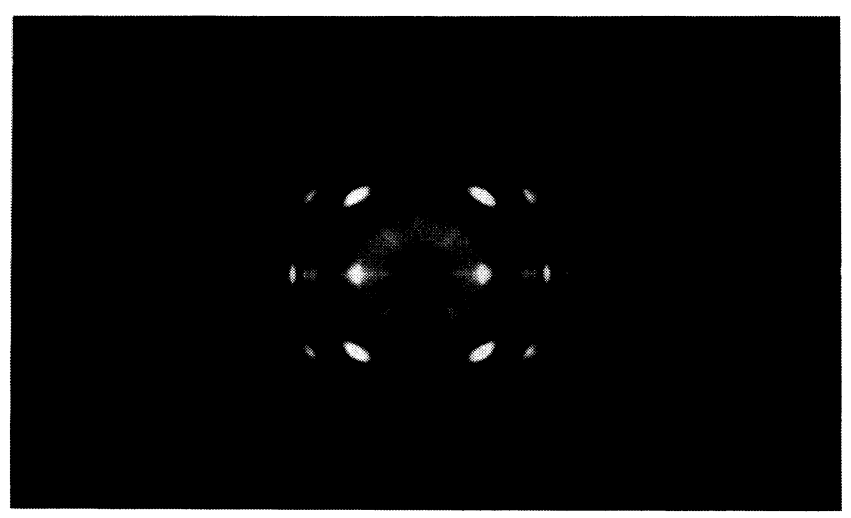

Figure 1. X-Ray fiber diagram of PVDC obtained by the canal polymerization. 
The function for the internal rotation barriers was the three-minimum sinusoidal type, and the barrier height was assumed to be 2.0

Table I. Parameters for van der Waals interactions

\begin{tabular}{|c|c|c|}
\hline Atom pair & $\varepsilon / \mathrm{kcal} \mathrm{mol}^{-1}$ & $r_{\min } / \AA$ \\
\hline $\mathrm{C} \cdots \mathrm{C}$ & 0.120 & 3.40 \\
\hline C $\cdots C l$ & 0.287 & 3.45 \\
\hline C $\cdots H$ & 0.108 & 2.90 \\
\hline $\mathrm{Cl} \cdots \mathrm{Cl}$ & 0.688 & 3.50 \\
\hline $\mathrm{Cl} \cdots \mathrm{H}$ & 0.250 & 2.95 \\
\hline $\mathrm{H} \quad \cdots \mathrm{H}$ & 0.122 & 2.40 \\
\hline
\end{tabular}

$U_{i j}=\varepsilon_{i j}\left[\left(r_{\min } / r_{i j}\right)^{12}-2\left(r_{\min } / r_{i j}\right)^{6}\right]$ $\mathrm{kcal} \mathrm{mol}^{-1} \cdot{ }^{14,15}$ The potential function for the van der Waals interactions between nonbonded atoms was approximated by the Lennard-Jones "6-12" function. The parameters used for the van der Waals interactions

Table II. Parameters for bending energies

\begin{tabular}{ccc}
\hline Angle & $k / \mathrm{kcal} \mathrm{mol}^{-1} \mathrm{rad}^{-2}$ & $\theta_{0} /$ degree \\
\hline$\theta_{1}\left(\mathrm{C}-\mathrm{CH}_{2}-\mathrm{C}\right)$ & 107.2 & 112.0 \\
$\theta_{2}\left(\mathrm{C}-\mathrm{CCl}_{2}-\mathrm{C}\right)$ & 144.8 & 112.0 \\
$\theta_{3}(\mathrm{C}-\mathrm{C}-\mathrm{H})$ & 92.8 & 109.5 \\
$\theta_{4}(\mathrm{C}-\mathrm{C}-\mathrm{Cl})$ & 157.1 & 109.5 \\
\hline
\end{tabular}

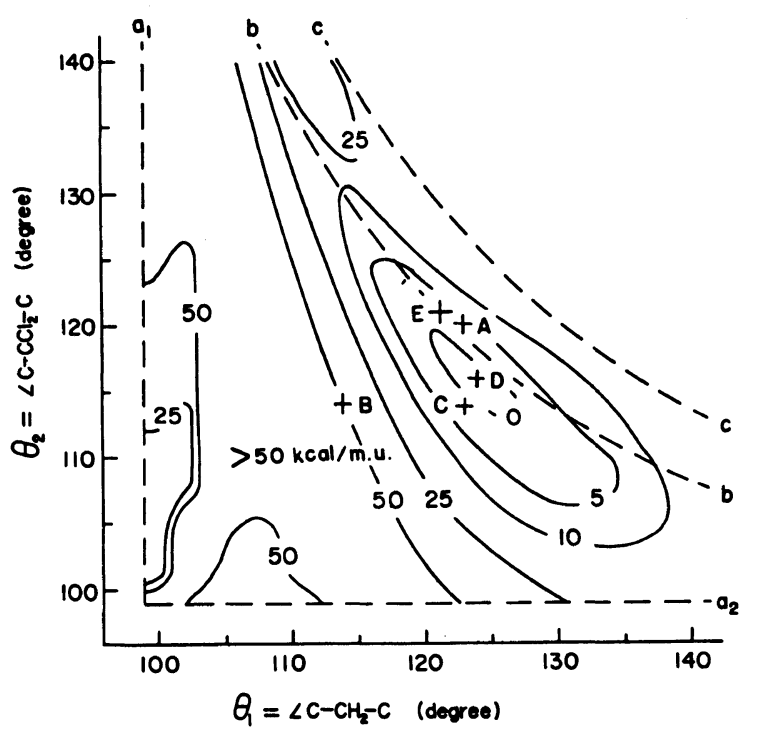

$\begin{array}{llllll}A & B & C & D & E & a_{2}\end{array}$

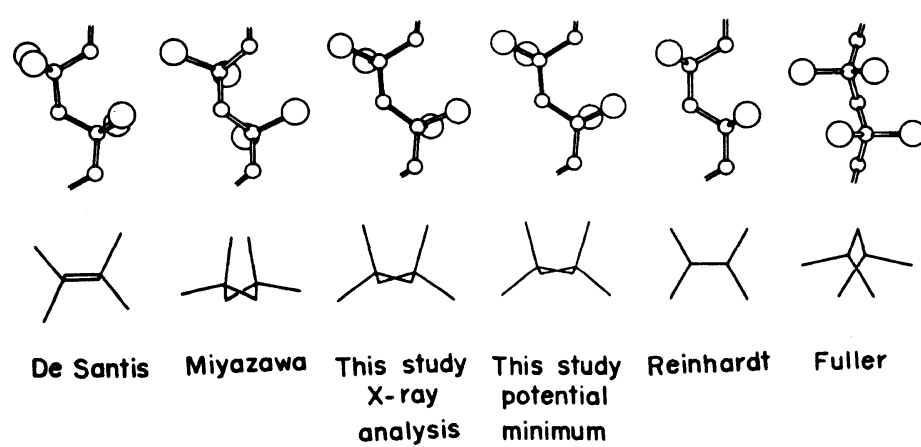

Figure 2. Conformational energy contour map against two backbone bond angles, and several molecular models of PVDC. The Fuller's model will be located anywhere on the line $a_{2}$. 
are listed in Table $\mathrm{I}^{16-18}$ The electrostatic interactions were estimated by the use of point dipole-point dipole interaction equation. The point dipole was assumed to be at the midpoint of the $\mathrm{C}-\mathrm{Cl}$ bond. The value of $\mathrm{C}-\mathrm{Cl}$ bond moment was taken as 2.0 debyes from the data for 2,2-dichloropropane and 2-chloropropane. ${ }^{19}$ The value of the dielectric constant was assumed to be $40 .^{20,21}$ The van der Waals interactions and electrostatic interactions were considered in a distance of $10 \AA$ and $40 \AA$, respectively.

The bending energy was estimated by

$$
E=(1 / 2) k\left(\theta-\theta_{0}\right)^{2}
$$

where $\theta_{0}$ is the bond angle $\theta$ in the zero strain condition, and $k$ is the force constant for the bending. The constant $k$ and $\theta_{0}$ were assumed as listed in Table II. ${ }^{6}$ The total bending energy is the sum of the contributions from the bond angles $\theta_{1}\left(\mathrm{C}-\mathrm{CH}_{2}-\mathrm{C}\right), \theta_{2}(\mathrm{C}-\mathrm{CCl}-\mathrm{C}), \theta_{3}(\mathrm{C}-\mathrm{C}-$ $\mathrm{H})$, and $\theta_{4}(\mathrm{C}-\mathrm{C}-\mathrm{Cl})$.

Figure 2 shows the map of the total energy represented with energy-level contour vs. $\theta_{1}$ and $\theta_{2}$. Here we obtained the following equations which define the PVDC chain conformation (see Appendix).

$$
\left(1-\cos \theta_{1}\right)\left(1-\cos \theta_{2}\right)-I^{2} / r^{2} \gtreqless 0
$$

where $I$ is the axial pitch of monomeric unit, i.e., $4.68 \AA / 2=2.34 \AA$, and $r$ is the $\mathrm{C}-\mathrm{C}$ bond length, $1.54 \AA$. In the region surrounded by the lines $a_{1}, a_{2}$, and $b$, the value of eq 2 is negative, and in this region the molecular chain takes some glide conformation. In the region between the lines $b$ and $c$, the value of eq 2 is positive, and the molecular chain has some $2 / 1$ helical conformation. The value of eq 2 is zero on the border line $b$. The Reinhardt tub model (cross E in Figure 2) is on this line. Other three border lines are expressed as follows.

$$
\begin{aligned}
& \text { line } \mathrm{a}_{1} ; \cos \theta_{1}=1-I^{2} /\left(2 r^{2}\right) \\
& \text { line } \mathrm{a}_{2} ; \cos \theta_{2}=1-I^{2} /\left(2 r^{2}\right) \\
& \text { line } \mathrm{c} ; \cos \theta_{1}+\cos \theta_{2}+I^{2} /\left(2 r^{2}\right)=0
\end{aligned}
$$

No molecular model can exist in outer region of the three lines, $a_{1}, a_{2}$, and $c$. The Fuller's model will be located anywhere on the line $a_{2}$. The crosses $\mathrm{A}$ and $\mathrm{B}$ correspond to the $2 / 1$ helical model by De Santis et al. and the glide model by Miyazawa and Ideguchi, respectively. The position of the conformational energy minimum is shown by the cross $\mathrm{D}\left(\theta_{1}=\right.$ $124^{\circ}$ and $\theta_{2}=116^{\circ}$ ). This energy minimum is near the border line $b$, and the resulting molecular conformation is of glide type. The cross $\mathrm{C}$ represents the conformation obtained by the present X-ray analysis as shown later.

\section{Molecular Transform}

The cylindrically averaged $\mathrm{X}$-ray diffraction intensities scattered by one polymer chain, socalled molecular transform $|T|^{2}$, was evaluated by the following equation ${ }^{22}$ for the PVDC molecular model proposed so far, where the chain axis was taken as the $c$ axis instead of the $b$ axis which is the fiber axis in the following crystal structure analysis.

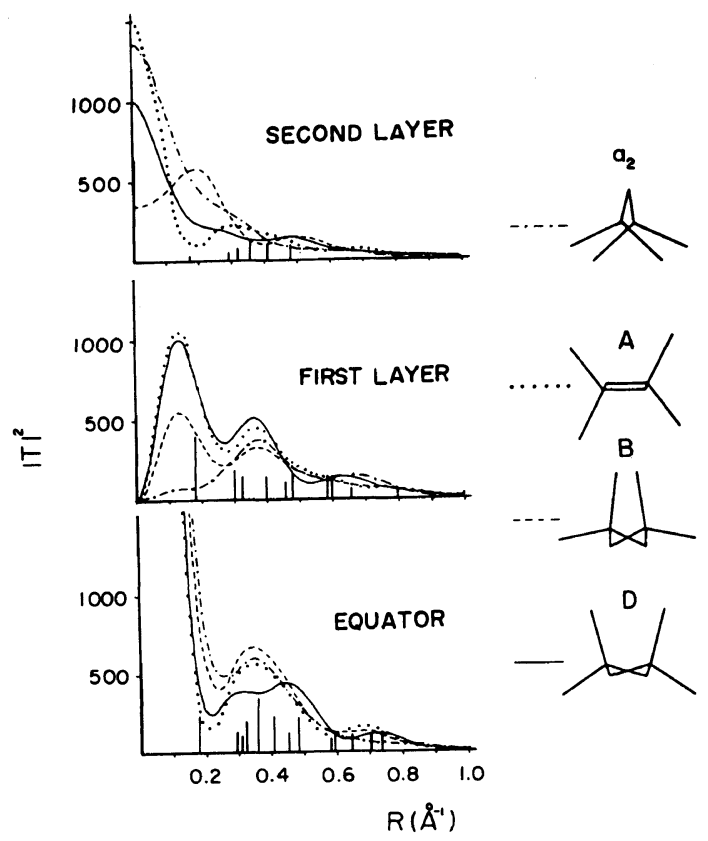

Figure 3. Comparison between observed reflection intensities (vertical rods) and the cylindrically averaged intensities $|T|^{2}$ for several molecular models. Letters, $\mathrm{a}_{2}$, $\mathrm{A}$, and so on have the same meaning as in Figure 2. 


$$
\begin{aligned}
|T|^{2}= & \left\langle|F(R, \psi, 1 / c)|^{2}\right\rangle_{\psi} \\
= & \sum_{i} \sum_{j} f_{i} f_{j} J_{0}\left(2 \pi R r_{i j}\right) \exp \left(2 \pi i l z_{i j} / c\right) \\
& \times \exp \left(-2 B \sin ^{2} \theta / \hat{\lambda}^{2}\right)
\end{aligned}
$$

where $(R, \psi, 1 / c)$ are the cylindrical coordinates in the reciprocal space, $f$ is the atomic scattering factor, $J_{0}$ is the Bessel function of zero order, and $r_{i j}$ and $z_{i j}$ are the radial and axial components of the interatomic distance between $i$ th and $j$ th atoms in the fiber period. A thermal parameter $B$ of $5 \AA^{2}$ was assumed.

Figure 3 shows the calculated intensity curves for the typical models. The vertical rods in the figure indicate the observed reflection intensities. The Fuller's model cannot inter-

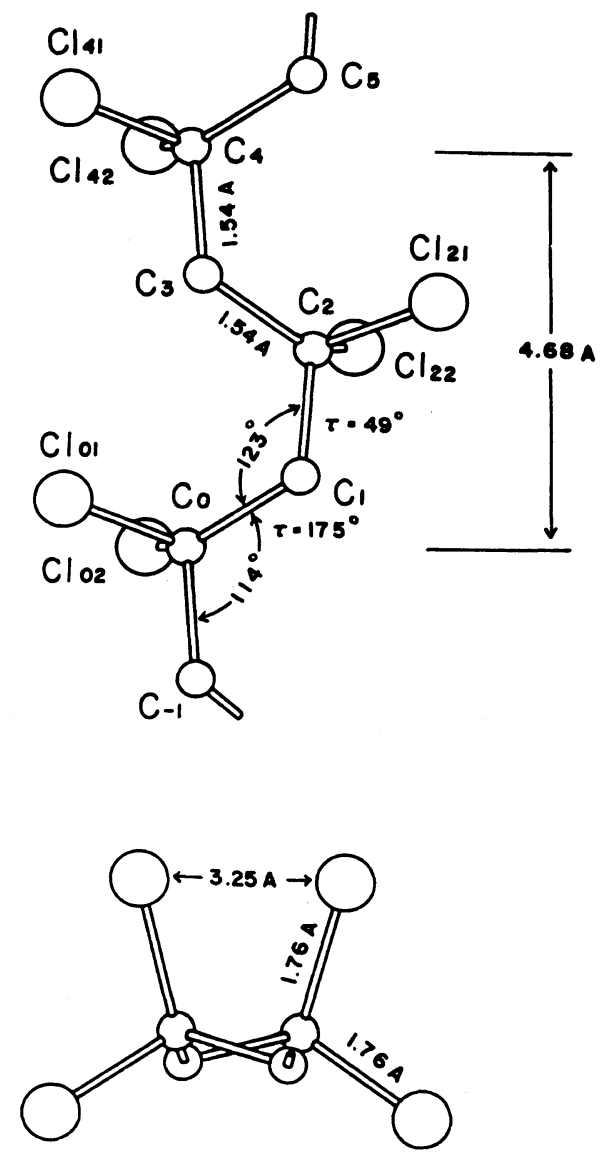

Figure 4. Bond lengths, bond angles, and internal rotation angles $(\tau)$ of the PVDC chain obtained by the present X-ray analysis. pret the strongest reflection on the first layer line, while the Miyazawa's model does not explain the remarkably intense meridional reflection of the second layer line. Both the glide model obtained by the present energy calculation and the 2/1 helical model by De Santis et al. give sufficient interpretation for the reflection intensities. Accordingly, it was impossible to decide which is favorable from the result of the molecular transform alone.

\section{Unit Cell and Space Group}

All reflections observed in the fiber diagram were indexed by a monoclinic cell with cell dimensions $a=6.71 \AA, b($ fiber axis $)=4.86 \AA$, $c=12.51 \AA$ and $\beta=123^{\circ}$. From the systematic
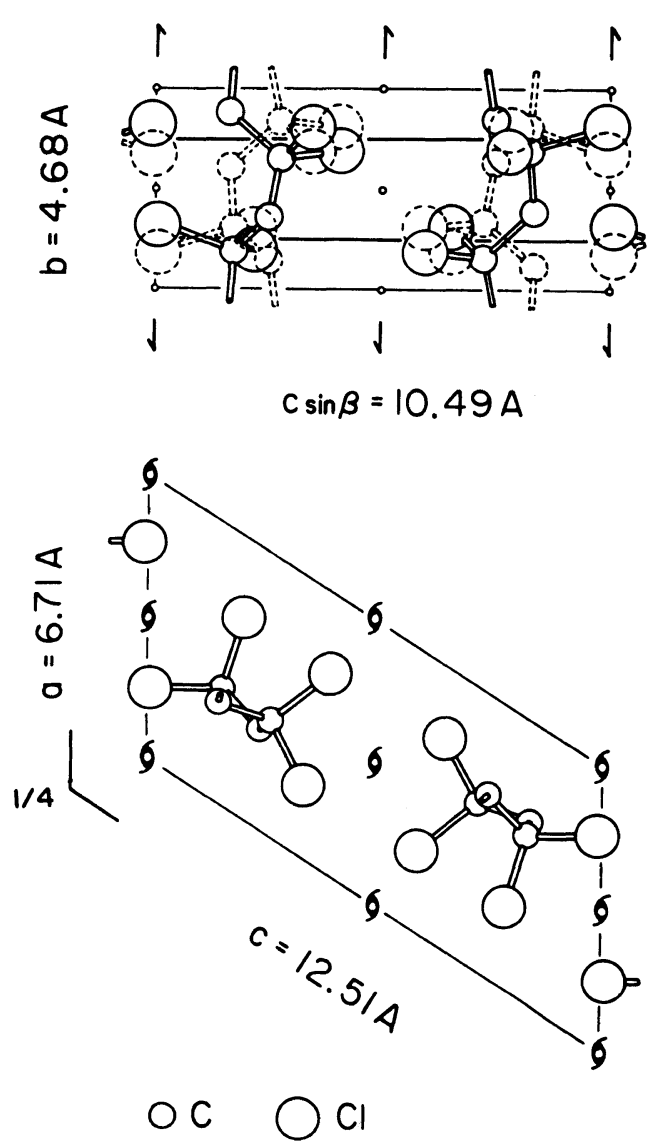

Figure 5. Crystal structure of PVDC. Molecular chains shown by solid and broken lines indicate upward and downward chains, respectively. 
absence of reflections, $0 k 0$ when $k$ is odd, the possible space groups are $\mathrm{P} 2_{1}$ and $\mathrm{P} 2_{1} / \mathrm{m}$. The calculated density assuming four monomeric units (two chains) in the unit cell is $1.95 \mathrm{~g}$ $\mathrm{cm}^{-3}$, which is reasonable comparing with the observed density of $1.859 \mathrm{~g} \mathrm{~cm}^{-3}$ for commercial PVDC. ${ }^{11}$ The cell dimensions are essentially the same as those reported by Okuda. ${ }^{12}$

\section{Determination of Crystal Structure}

We searched at first the molecular packing projected onto the ac plane for both the glide model obtained by the energy calculation and the $2 / 1$ helical model by De Santis et al. adopting the plane group $\mathrm{P} 2$ (both $\mathrm{P} 2{ }_{1}$ and $\mathrm{P} 2 / \mathrm{m}$ possess the plane group $\mathrm{P} 2$ in the ac plane). Because of the major contribution of chlorine atoms to the reflection intensities, the $x$ and $z$ coordinates of heavy chlorine atoms were determined unequivocally. Referring the $(x, z)$ coordinates of chlorine atoms, both glide and $2 / 1$ helical models still remained feasible, depending on the location of carbon atoms (as for the positions of chlorine atoms, see the bottom figure in Figure 5). Namely, if the 2/1 helical model is the case, two helical chains in the unit cell must be situated such that their chain axes coincide with non-equivalent two twofold screw axes parallel to the $b$ axis at $(x=$ $0.5, z=0.0)$ and $(x=0.5, z=0.5)$ (see Figure 5). In this case, therefore, the two chains are crystallographically non-equivalent. On the other hand, when the glide model is the case, the two chains are related by one of the two twofold screw axes, but in this case two monomeric units in the chain are non-equivalent.

Trial and error procedure for all $h k l$ reflections adopting the space group $\mathrm{P} 2_{1}$ indicated that agreement between observed and calculated structure factors for the glide model was more satisfactory than the $2 / 1$ helical model. However, the glide model still remained appreciable discrepancies between observed and calculated structure factors for weak or non-observed refections. This trouble- some could be settled up by introducing a statistical arrangement of the polymer chains with respect to their chain direction. Namely, when upward and downward molecular chains exist in equal probability, the space group $\mathrm{P} 2 / \mathrm{m}$ is considered to be reasonable. Accordingly, further refinement of the glide model and also the $2 / 1$ helical model in the $\mathrm{P} 2{ }_{1} / \mathrm{m}$ lattice was carried out. For the helical model, there exist right-handed and lefthanded helices. Therefore, the combination about the chain direction and the helical sense of the two chains in the unit cell generate 12 different crystal structures in the case of $\mathrm{P} 2$ and 6 in $\mathrm{P} 21 / \mathrm{m}$.

The final discrepancy factors $R\left(=\sum \mid \sqrt{I_{0}}\right.$ $-\sqrt{I_{\mathrm{c}}} \mid / \sum \sqrt{I_{0}}$, where $I=m F^{2} ; m$, multiplicity; $F$, structure factor) for the four different type crystal structures are shown in Table III; in the table the smallest $R$ values are listed up for the $2 / 1$ helical model among the many different crystal structures, and the $R$ values were estimated for observed reflections only, and a thermal parameter of $6 \AA^{2}$ was employed for the calculated structure factors.

Although the glide structure in the $\mathrm{P} 2_{1}$ cell is

Table III. Final discrepancy factors, $R$

\begin{tabular}{ccc}
\hline Molecular conformation & Space group & $R / \%$ \\
\hline Glide & $\mathrm{P} 2_{1} / \mathrm{m}$ & 15 \\
- & $\mathrm{P} 2_{1}$ & 20 \\
\hline & $\mathrm{P} 2_{1} / \mathrm{m}$ & 30 \\
$(2 / 1)$ Helix & $\mathrm{P} 2_{1}$ & 31 \\
\hline
\end{tabular}

Table IV. Atomic coordinates

\begin{tabular}{lccc}
\hline Atom & $x / a$ & $y / b$ & $z / c$ \\
\hline $\mathrm{C}_{0}$ & 0.415 & 0.191 & 0.166 \\
$\mathrm{C}_{1}$ & 0.350 & 0.373 & 0.245 \\
$\mathrm{C}_{2}$ & 0.415 & 0.691 & 0.273 \\
$\mathrm{C}_{3}$ & 0.350 & 0.873 & 0.158 \\
$\mathrm{Cl}_{01}$ & 0.244 & 0.309 & 0.006 \\
$\mathrm{Cl}_{02}$ & 0.717 & 0.192 & 0.218 \\
$\mathrm{Cl}_{21}$ & 0.244 & 0.809 & 0.334 \\
$\mathrm{Cl}_{22}$ & 0.717 & 0.692 & 0.399 \\
\hline
\end{tabular}


Crystal Structure of Poly(vinylidene chloride)

Table V. Comparison between observed and calculated structure factors

\begin{tabular}{|c|c|c|c|c|c|c|}
\hline$h k l$ & $\sqrt{I_{0}}$ & $\sqrt{I_{\mathrm{c}}}\left(\mathrm{P} 2_{1} / \mathrm{m}\right) \quad \sqrt{I_{\mathrm{c}}}\left(\mathrm{P} 2_{1}\right)$ & $h k l$ & $\sqrt{I_{0}}$ & $\sqrt{I_{\mathrm{c}}}\left(\mathrm{P} 2_{1} / \mathrm{m}\right)$ & $\sqrt{I_{\mathrm{c}}}\left(\mathrm{P} 2_{1}\right)$ \\
\hline 001 & - & 7 & 106 & - & 1 & \\
\hline$\overline{1} 01$ & - & 4 & $\overline{4} 08$ & & & \\
\hline$\overline{1} 02\}$ & & & 400 & & & \\
\hline 100$\}$ & 63 & 49 & $\overline{3} 09$ & 30 & 3 & \\
\hline 002 & 36 & 31 & $\overline{2} 09$ & & & \\
\hline$\overline{1} 03$ & - & 3 & 303 & & & \\
\hline 101 & 1 & 6 & $205]$ & & & \\
\hline 003$\}$ & & & $\overline{505}$ & & & \\
\hline$\overline{2} 02\}$ & 37 & 35 & $\overline{504}$ & & & \\
\hline$\overline{2} 03\}$ & & & $\overline{5} 06$ & 40 & 3 & \\
\hline$\overline{2} 01\}$ & 35 & 29 & 008 & & & \\
\hline$\overline{104}\}$ & & & $\overline{4} 09$ & & & \\
\hline 102$\}$ & 40 & 46 & 011 & - & 6 & 11 \\
\hline$\overline{2} 04\}$ & & & 111 & - & 8 & 15 \\
\hline 200$\}$ & 63 & 79 & $\overline{1} 12$ & & & \\
\hline 004 & 18 & 11 & 110 & 82 & 92 & 93 \\
\hline$\overline{105}$ & & & 012 & & & \\
\hline 103 & & & $\overline{1} 13$ & - & 11 & 12 \\
\hline$\overline{2} 05$ & 49 & 50 & 111 & - & 9 & 19 \\
\hline $201 J$ & & & $013\}$ & & & \\
\hline$\overline{3} 03]$ & & & $\overline{2} 12\}$ & 51 & 45 & 45 \\
\hline$\overline{3} 04$ & 34 & 41 & $\overline{2} 13\}$ & & & \\
\hline$\overline{3} 02$ & & & $\overline{2} 11\}$ & Medium & 36 & 37 \\
\hline 005 & & & $\overline{1} 14\}$ & & & \\
\hline$\overline{2} 06$ & & & $112\}$ & 45 & 40 & 52 \\
\hline$\overline{3} 05$ & 48 & 52 & $\overline{2} 14$ & - & 2 & 16 \\
\hline 202 & & & 210 & - & 0 & 0 \\
\hline$\overline{3} 01\}$ & & & 014 & - & 18 & 19 \\
\hline$\overline{106}\}$ & & & $\overline{1} 15$ & & & \\
\hline 104$\}$ & 23 & 35 & 113 & & & \\
\hline$\overline{3} 06$ & - & 2 & $\overline{2} 15$ & 40 & 42 & 45 \\
\hline 300 & - & 19 & 211 & & & \\
\hline$\overline{2} 07$ & - & 0 & $\overline{3} 13$ & & & \\
\hline 203 & - & 27 & $\overline{3} 14$ & 34 & 40 & 42 \\
\hline 006 & - & 11 & $\overline{3} 12$ & & & \\
\hline$\overline{307}$ & & & 015 & & & \\
\hline$\overline{107}\}$ & 28 & 34 & 216 & & & \\
\hline 105 & & & $\overline{3} 15$ & 41 & 45 & 49 \\
\hline 301 & & & 212 & & & \\
\hline$\overline{4} 04$ & 34 & 34 & $\overline{3} 11$ & & & \\
\hline$\overline{4} 05$ & & & $\overline{1} 16$ & - & 3 & 5 \\
\hline$\overline{4} 03$ & & & 114 & - & 5 & 16 \\
\hline$\overline{4} 06$ & - & 1 & $\overline{3} 16$ & - & 5 & 7 \\
\hline$\overline{4} 02$ & & & 310 & - & 0 & 0 \\
\hline$\overline{2} 08$ & & & $\overline{2} 17$ & - & 2 & 3 \\
\hline 204 & & & 213 & - & 15 & 17 \\
\hline$\overline{3} 08$ & & & 016 & - & 8 & 8 \\
\hline 302 & 29 & 30 & $\overline{3} 17$ & & & \\
\hline$\overline{4} 07$ & & & $\overline{1} 17$ & & & \\
\hline$\overline{4} 01$ & & & 311 & 40 & 42 & 44 \\
\hline 007 & & & 115 & & & \\
\hline$\overline{108}$ & - & 2 & & & & \\
\hline
\end{tabular}


Table V. (continued)

\begin{tabular}{|c|c|c|c|c|c|c|c|}
\hline$h k l$ & $\sqrt{I_{0}}$ & $\sqrt{I_{\mathrm{c}}}\left(\mathrm{P} 2_{1} / \mathrm{m}\right)$ & $\sqrt{I_{c}}\left(\mathbf{P} 2_{1}\right)$ & $h k l$ & $\sqrt{I_{0}}$ & $\sqrt{I_{\mathrm{c}}}\left(\mathrm{P} 2_{1} / \mathrm{m}\right)$ & $\sqrt{I_{\mathrm{c}}}\left(\mathbf{P} 2_{1}\right)$ \\
\hline$\overline{4} 14$ & \multirow{4}{*}{43} & \multirow{5}{*}{25} & \multirow{4}{*}{28} & 121 & - & 5 & 30 \\
\hline $\begin{array}{l}\overline{4} 13 \\
\overline{4} 15\end{array}$ & & & & $\left.\begin{array}{l}023 \\
222\end{array}\right\}$ & 17 & 17 & 26 \\
\hline$\overline{2} 18$ & & & & $\overline{2} 23$ & - & 4 & 18 \\
\hline 214 & & & & $\overline{2} 21$ & - & 15 & 23 \\
\hline$\overline{3} 18$ & & & \multirow{5}{*}{25} & $\left.\begin{array}{l}\overline{1} 24 \\
122\end{array}\right\}$ & 22 & 23 & 24 \\
\hline $\begin{array}{l}312 \\
\overline{4} 17\end{array}$ & \multirow[t]{5}{*}{28} & \multirow[t]{5}{*}{21} & & $\begin{array}{l}122\} \\
\overline{2} 24\end{array}$ & 22 & & \\
\hline$\overline{4} 11$ & & & & $\left.\begin{array}{l}224 \\
220\end{array}\right\}$ & 26 & 34 & 34 \\
\hline 017 & & & & 024 & - & 4 & 6 \\
\hline 410 & & & & $\overline{1} 25$ & & & \\
\hline 313 & & & \multirow{4}{*}{27} & 123 & 27 & 22 & 23 \\
\hline$\overline{2} 19$ & \multirow{4}{*}{33} & \multirow{4}{*}{27} & & $\overline{2} 25$ & 21 & 22 & 23 \\
\hline$\overline{3} 19$ & & & & $221 J$ & & & \\
\hline 215 & & & & $\overline{3} 23$ & - & 5 & 6 \\
\hline $\begin{array}{l}\overline{5} 15 \\
015\end{array}$ & & & \multirow{2}{*}{14} & $\left.\begin{array}{l}\overline{3} 24 \\
\overline{3} 22\end{array}\right\}$ & Weak & 17 & 18 \\
\hline $\begin{array}{l}021 \\
\overline{1} 21\end{array}$ & - & 0 & & $\begin{array}{l}322 \\
025\end{array}$ & & & \\
\hline$\overline{1} 22$ & \multirow{2}{*}{12} & \multirow{3}{*}{13} & \multirow{3}{*}{37} & $\overline{2} 26$ & & & \\
\hline 120 & & & & $\overline{3} 25$ & 22 & 23 & 37 \\
\hline 022 & & & & 222 & & & \\
\hline$\overline{1} 23$ & - & 2 & 3 & $\overline{3} 21$ & & & \\
\hline
\end{tabular}

not always denied, there are several large calculated structure factors for non-observed reflections, especially on the second layer line as shown in Table $\mathrm{V}$. Therefore, the glide structure in the $\mathrm{P} 2_{1} / \mathrm{m}$ cell is the most favorable. The atomic coordinates for the glide structure in the $\mathrm{P} 2_{1} / \mathrm{m}$ cell are given in Table IV.

\section{RESULTS AND DISCUSSION}

\section{Molecular Structure}

It has been revealed that the molecular chain of PVDC takes a glide conformation of $T G^{\prime} T \bar{G}^{\prime}$ type in the crystal, although the two successive monomeric units in the chain are non-equivalent in the crystallographic sense. In more detail, the internal rotation angles of the backbone bonds are $175^{\circ}(T)$ and $49^{\circ}\left(G^{\prime}\right)$, the latter deviates appreciably from the exact gauche form $\left(60^{\circ}\right)$.

The set of the backbone bond angles $\left(\theta_{1}=\right.$ $123, \theta_{2}=114^{\circ}$ ) obtained by the present X-ray study nearly agrees with the set for the glide model obtained by the conformational energy calculation $\left(\theta_{1}=124^{\circ}, \theta_{2}=116^{\circ}\right)$. Although the $\mathrm{C}-\mathrm{CCl}_{2}-\mathrm{C}$ bond angle of $114^{\circ}$ is close to $112^{\circ}$ as on the average in linear hydrocarbons, the $\mathrm{C}-\mathrm{CH}_{2}-\mathrm{C}$ bond angle opens to $123^{\circ}$. Such large $\mathrm{C}-\mathrm{CH}_{2}-\mathrm{C}$ bond angles have been reported for polyisobutylene $\left(128^{\circ}\right)^{23}$ and 2,2,3,4-tetra-methyladipic acid $\left(122.6^{\circ}\right) .^{24}$ There is an extremely close intramolecular $\mathrm{Cl} \cdots \mathrm{Cl}$ contact of $2.35 \AA$, between adjacent $\mathrm{CCl}$ groups in the Miyazawa's model, which seems again inadequate from the consideration of the molecular transform. The glide conformation obtained by the $\mathrm{X}$-ray study has the shortest $\mathrm{Cl} \cdots \mathrm{Cl}$ contact of $3.25 \AA$, which is near unreasonable as the intramolecular contact. For example, the closest methyl... methyl carbon distance in polyisobutylene is only $3.02 \AA$ in spite of the opening of $\mathrm{C}-\mathrm{CH}_{2}-$ $\mathrm{C}$ bond angle to $128^{\circ}$. Therefore, it is certain that the $\mathrm{Cl} \cdots \mathrm{Cl}$ repulsion is released by the large opening of $\mathrm{C}-\mathrm{CH}_{2}-\mathrm{C}$ bond angle as 
well as the deviation of one internal rotation angle of the backbone from $60^{\circ}$ to $49^{\circ}$.

The glide conformation of PVDC chain is similar to that of poly(vinylidene fluoride) in the form $\mathrm{II}^{25}$ : the internal rotation angles of the PVDC chain are very close to those of poly(vinylidene fluoride) chain $\left(175^{\circ}\right.$ and $\left.45^{\circ}\right)$. In the poly(vinylidene fluoride) chain, however, the closest intramolecular $F \cdot \cdot \mathrm{F}$ distance of $2.70 \AA$, which is equal to the sum of van der Waals radii, is preserved by a still smaller $\mathrm{C}-\mathrm{CH}_{2}-\mathrm{C}$ bond angle, $116^{\circ}$, as compared with $123^{\circ}$ in PVDC.

Poly(vinylidene fluoride) exhibits polymorphism, and several molecular conformations appear by the transformation between repulsion of $\mathrm{CCl}$ groups will restrict a variation of the molecular conformation, and thus no polymorph has been found for PVDC.

\section{Crystal Structure}

A copolymer of PVDC with $20 \mathrm{~mol} \%$ vinyl chloride, which exhibits essentially the same Xray diffraction pattern as that of the PVDC homopolymer, could be doubly oriented by rolling: the rolled plane was found to be parallel to the (100) plane. The molecular packing of PVDC determined by this study may

Table VI. Intermolecular atomic distances less than $4.0 \AA^{\mathrm{a}}$

\begin{tabular}{|c|c|c|c|c|}
\hline \multicolumn{2}{|c|}{$\begin{array}{l}\text { Between molecules of } \\
\text { the same direction } / \AA\end{array}$} & \multicolumn{3}{|c|}{$\begin{array}{c}\text { Between upward and } \\
\text { downward molecules } / \AA\end{array}$} \\
\hline $\cos 1$ & $\cdots \mathrm{Cl}_{01}$ (B) 3.36 & $\mathrm{C}_{3}(\mathrm{~L})$ & $\mathrm{Cl}_{01}(\mathrm{~B})$ & 3.45 \\
\hline $\mathrm{C}_{2}(\mathrm{~A})$ & $\cdots \mathrm{Cl}_{01}$ (B) 3.91 & $\mathrm{C}_{1}(\mathrm{~K})$ & $\mathrm{Cl}_{01}(\mathrm{C})$ & 3.79 \\
\hline $\mathrm{L}_{01}(\mathrm{~A})$ & $\cdots \mathrm{Cl}_{02}(\mathrm{H}) 3.46$ & & (B) & 3.87 \\
\hline $\mathrm{Cl}_{21}(\mathrm{D})$ & $\cdot \mathrm{Cl}_{02}(\mathrm{~F}) \quad 3.50$ & L) & $\cdots \mathrm{Cl}_{22}(\mathrm{I})$ & 3.6 \\
\hline $\mathrm{Cl}_{21}(\mathrm{~A})$ & $\cdots \mathrm{Cl}_{01}$ (B) 3.70 & $\mathrm{Cl}_{21}(\mathrm{~L})$ & $\cdots \mathrm{El}_{01}(\mathrm{~B})$ & 3.74 \\
\hline $\mathrm{Cl}_{01}(\mathrm{~A})$ & $\cdots \mathrm{Cl}_{01}$ (A) 3.95 & $\mathrm{Cl}_{02}(\mathrm{~K})$ & $\cdots \mathrm{Cl}_{01}(\mathrm{H})$ & 3.78 \\
\hline \multirow[t]{2}{*}{$\mathrm{Cl}_{22}(\mathrm{~A})$} & $\cdots \mathrm{Cl}_{22}(\mathrm{G}) 3.98$ & & $\cdots \mathrm{Cl}_{02}(\mathrm{~J})$ & 3.81 \\
\hline & & $\mathrm{Cl}_{02}$ & $\cdots \mathrm{Cl}_{22}(\mathrm{E})$ & 3.86 \\
\hline
\end{tabular}

a Symmetry relationship in fractional atomic coordinates A: $x, y, z ; \mathrm{B}:-x, 0.5+y,-z ; \mathrm{C}:-x,-0.5+y$, $-z$; D: $1-x,-0.5+y, 1-z ; \mathrm{E}: 1+x, y, z ; \mathrm{F}: 2-x$, $0.5+y, 1-z ; \mathrm{G}: 2-x,-0.5+y, 1-z ; \mathrm{H}: 1-x, 0.5+y$, $-z ; \mathrm{I}:-x, 0.5+y, 1-z ; \mathrm{J}:-1+x, y, z ; \mathrm{K}: x, 0.5-y, z$; L: $x, 1.5-y, z$. interpret well this feature. Namely, as shown in the ac projection of the crystal structure, the crystal is composed of the sheets of molecules parallel to the (100) plane.

The systematic absence of reflections cannot tell us the space group unequivocally; $\mathrm{P} 2_{1}$ and $\mathrm{P} 2_{1} / \mathrm{m}$ were remained as the possible space group. However, the space group $\mathrm{P} 2_{1} / \mathrm{m}$ gave better explanation of the reflection intensities. This $\mathrm{P} 2 / \mathrm{m}$ cell suggests the possibility of disorder with respect to the polymer chain direction, i.e., either upward or downward chain occupies one site in the crystal lattice with equal probability. This statistical structure is never unreasonable in the view of packing of molecular chains: some close intermolecular atomic distances are shown in Table VI.

Acknowledgements. The authors wish to express their sincere thanks to Dr. K. Okuda of Kureha Chemical Industry Co., Ltd. for his helpful discussions and supplying PVDC samples.

\section{APPENDIX}

The backbone atoms of glide and $2 / 1$ helical models are settled in a Cartesian coordinate system as shown in the top and bottom figures in Figure 6, respectively. The $\mathrm{C}-\mathrm{C}$ bond length and the axial pitch of monomeric unit along the fiber axis are expressed as $r(=1.54 \AA)$ and $I(=b / 2=2.34 \AA)$. For the glide model, the distance between atoms 1 and $1^{\prime}$, and atoms 2 and $2^{\prime}$ are

$$
\begin{aligned}
& \left(2 y_{1}\right)^{2}+I^{2}=2 r^{2}\left(1-\cos \theta_{2}\right) \\
& \left(2 y_{2}\right)^{2}+I^{2}=2 r^{2}\left(1-\cos \theta_{1}\right)
\end{aligned}
$$

where $\theta_{1}$ and $\theta_{2}$ are the backbone bond angles. For the glide model, two bond distances 12 and $21^{\prime}$ are

$$
\begin{aligned}
& x_{2}{ }^{2}+\left(y_{1}-y_{2}\right)^{2}+z_{2}{ }^{2}=r^{2} \\
& x_{2}{ }^{2}+\left(y_{1}+y_{2}\right)^{2}+\left(I-z_{2}\right)^{2}=r^{2}
\end{aligned}
$$




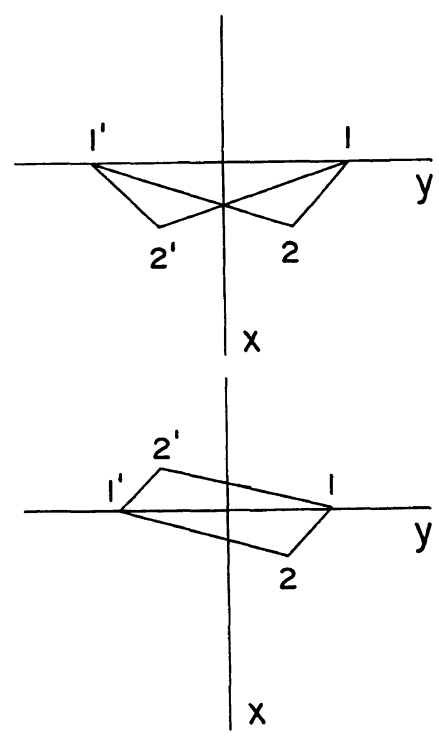

Figure 6. Setting of the backbone atoms of glide and $2 / 1$ helical models in a Cartesian coordinate system.

From the above four equations

$$
x^{2}=r^{2}-r^{4}\left(1-\cos \theta_{1}\right)\left(1-\cos \theta_{2}\right) / I^{2}
$$

Since $x_{2}^{2}$ should be positive,

$$
\left(1-\cos \theta_{1}\right)\left(1-\cos \theta_{2}\right)<I^{2} / r^{2}
$$

(A-5) is the condition that the glide model is allowable.

For the 2/1 helix, instead of (A-2)

$$
\left(2 x_{2}\right)^{2}+\left(2 y_{2}\right)^{2}+I^{2}=2 r^{2}\left(1-\cos \theta_{1}\right)
$$

Therefore, similarly

$$
\begin{aligned}
& \left(-4 y_{1}{ }^{2} / I^{2}\right) x_{2}{ }^{2} \\
& \quad=r^{2}-r^{4}\left(1-\cos \theta_{1}\right)\left(1-\cos \theta_{2}\right) / I^{2}<0
\end{aligned}
$$

Thus the condition that the $2 / 1$ helix can exist is

$$
\left(1-\cos \theta_{1}\right)\left(1-\cos \theta_{2}\right)>I^{2} / r^{2}
$$

The equation of the border line $b$ in Figure 2 separating the two regions in which the glide and $2 / 1$ helical models are allowable, respectively, is

$$
\left(1-\cos \theta_{1}\right)\left(1-\cos \theta_{2}\right)=I^{2} / r^{2}
$$

The border lines $a_{1}$ and $a_{2}$ in Figure 2 are obtained from (A-1) and (A-2).

$$
\begin{aligned}
& \text { line } \mathrm{a}_{1}: \cos \theta_{1}=1-I^{2} / 2 r^{2} \\
& \text { line } \mathrm{a}_{2}: \cos \theta_{2}=1-I^{2} / 2 r^{2}
\end{aligned}
$$

Therefore $\theta_{1}=\theta_{2}=98.9^{\circ}$.

As for the border line c, i.e., the upper limit of the bond angles, the distance between atoms 2 and $2^{\prime}, d$ is

$$
\begin{aligned}
d^{2} & =\left(2 x_{2}\right)^{2}+\left(2 y_{2}\right)^{2}+I^{2} \\
& =4 R^{2}+I^{2}
\end{aligned}
$$

where $R^{2}=x_{2}{ }^{2}+y_{2}{ }^{2}$.

Here $\theta_{1}$ is maximum when $d$ is maximum, and $d$ is maximum when $R$ is maximum. $R$ is maximum when $R=r \cos \left(\theta_{1} / 2\right)$.

$$
\begin{aligned}
d^{2}=2 r^{2}\left(1-\cos \theta_{2}\right) & =4 R^{2}+I^{2} \\
& \leqq 4\left\{r \cos \left(\theta_{1} / 2\right)\right\}^{2}+I^{2}
\end{aligned}
$$

Therefore,

$$
\cos \theta_{1}+\cos \theta_{2}+I^{2} / 2 r^{2}=0
$$

is the equation of the border line $c$.

\section{REFERENCES}

1. C. S. Fuller, Chem. Rev., 26, 143 (1940).

2. R. C. Reinhardt, Ind. Eng. Chem., 35, 422 (1943).

3. P. De Santis, E. Giglio, A. M. Liquori, and A. Ripamonti, J. Polym. Sci. A, 1, 1383 (1963).

4. V. M. Coiro, P. De Santis, A. M. Liquori, and A. Ripamonti, Rec. Sci., 33 (II-A), 1043 (1963).

5. V. M. Coiro, P. De Santis, and A. M. Liquori, $J$. Polym. Sci. B, 4, 821 (1966).

6. T. Miyazawa and Y. Ideguchi, J. Polym. Sci. B, 3, 541 (1965).

7. P. J. Hendra and J. R. Mackenzie, Spectrochim. Acta, 25A, 1349 (1969).

8. M. M. Coleman, M. S. Wu, I. R. Harrison, and P. C. Painter, J. Macromol. Sci. Phys., B15, 463 (1978).

9. M. S. Wu, P. C. Painter, and M. M. Coleman, J. Polym. Sci., Polym. Phys. Ed., 18, 95 (1980).

10. M. S. Wu, P. C. Painter, and M. M. Coleman, J. Polym. Sci., Polym. Phys. Ed., 18, 111 (1980).

11. S. Narita and K. Okuda, J. Polym. Sci., 38, 270 (1959).

12. K. Okuda, J. Polym. Sci. A, 2, 1749 (1964).

13. J. F. Brown, Jr. and D. M. White, J. Am. Chem. Soc., 82, 5671 (1960). 
14. R. A. Scott and H. A. Scheraga, J. Chem. Phys., 42, 2209 (1965).

15. R. A. Scott and H. A. Scheraga, J. Chem. Phys., 44, 3054 (1966).

16. A. Bondi, J. Phys. Chem., 68, 441 (1964).

17. J. Ketelaar, "Chemical Constitution," Elsevier Publishing Co., New York, N. Y., 1959, p 59.

18. K. S. Pitzer, Advan. Chem. Phys., 2, 59 (1959).

19. A. L. Mcclellan, "Tables of Experimental Dipole Moments," Freeman Publishing Co., San Francisco, 1963.

20. D. A. Brant and P. J. Flory, J. Am. Soc., 87, 663 (1965).

21. D. A. Brant and P. J. Flory, J. Am. Soc., 87, 2791 (1965).
22. Y. Chatani, Y. Okita, H. Tadokoro, and Y. Tamashita, Polym. J., 1, 555 (1970).

23. T. Tanaka, Y. Chatani, and H. Tadokoro, J. Polym. Sci., Polym. Phys. Ed., 12, 515 (1974).

24. E. Benedetti, C. Pedone, and G. Allegra, Macromolecules, 3, 16 (1970).

25. R. Hasegawa, Y. Takahashi, Y. Chatani, and H. Tadokoro, Polym. J., 3, 600 (1972).

26. Y. Takahashi and H. Tadokoro, Macromolecules, 13, 1316 (1980).

27. Y. Takahashi, H. Tadokoro, and A. Odajima, Macromolecules, 13, 1318 (1980).

28. Y. Takahashi, Y. Matsubara, and H. Tadokoro, Macromolecules, 15, 334 (1980). 